\title{
二阶多参考态微扰理论计算电子亲和势
}

\author{
范志辉 陈飞武* \\ (北京科技大学化学与生物工程学院化学与化工系; 功能分子与晶态材料科学与应用北京市重点实验室, 北京 100083)
}

摘要: 采用二阶多参考微扰理论计算了 $\mathrm{F}, \mathrm{Cl}, \mathrm{OH}, \mathrm{SH}, \mathrm{CN}, \mathrm{CH}_{2}$ 和 $\mathrm{NH}_{2}$ 的电子亲和势. 另外, 还考察了基函数 和完全活性空间大小对电子亲和势精度的影响. 通过和CASSCF, CASPT2, CCSD, CCSD(T), B3LYP, X3LYP, M06, HCTH, TPSS, B97D3, mPW2PLYP和B2PLYP的计算结果比较发现, 针对目前所用的基函数, 二阶多参考态微扰理论的总体计算效果是最好的.

关键词: 电子亲和势; 多参考态微扰理论; 基函数; 完全活性空间

中图分类号: 0641

\section{Computation of Electron Affinities with the Second Order Multireference Perturbation Theory}

\author{
FAN Zhi-Hui CHEN Fei-Wu* \\ (Department of Chemistry and Chemical Engineering, School of Chemistry and Biological Engineering, University of Science and \\ Technology Beijing; Beijing Key Laboratory for Science and Application of Functional Molecular and \\ Crystalline Materials, Beijing 100083, P. R. China)
}

\begin{abstract}
Electron affinities of $\mathrm{F}, \mathrm{Cl}, \mathrm{OH}, \mathrm{SH}, \mathrm{CN}, \mathrm{CH}_{2}$, and $\mathrm{NH}_{2}$ have been computed with the second order multireference perturbation theory. The effects of basis set and size of the complete active space on accuracy of electron affinity have also been investigated. The results are compared with calculations performed with CASSCF, CASPT2, CCSD, CCSD(T), B3LYP, X3LYP, M06, HCTH, TPSS, B97D3, mPW2PLYP, and B2PLYP. The overall performance of the second order multireference perturbation theory is best at the level of basis sets used in this study.
\end{abstract}

Key Words: Electron affinity; Multireference perturbation theory; Basis set; Complete active space

\section{Introduction}

Koopmans' theorem ${ }^{1}$ provides one simple approach to calculate theoretically the electron affinity (EA) at the Hartree-Fock level. However, due to the neglect of relaxation in Koopmans' theorem, the computed EA value at this level tends to be too small in comparison with the experimental data. To deal with this problem it is chosen to calculate the energies of a neutral species and its negative ion separately and take the difference as the EA. But it turns out that computing this difference is much challenging for computation chemistry, which requires a balanced description of both the neutral system and anion.
Since the anion has one more electron than its neutral counterpart its correlation energy is also larger than that of the latter. Therefore, a post Hartree-Fock calculation should be performed for obtaining an accurate EA value. The term "accurate" here will imply agreement with experiment to $0.1 \mathrm{eV}$ or better. However, this level of accuracy has been proven to be very difficult to achieve.

Density functional theory has been widely used to calculate the electron affinity as well as other properties of molecular systems, ${ }^{2-10}$ its accuracy depends on the basis set and the density functional used in the study. Multireference perturbation

Received: June 1, 2015; Revised: August 12, 2015; Published on Web: August 20, 2015.

"Corresponding author. Email: chenfeiwu@ustb.edu.cn; Tel: +86-10-62332689.

The project was supported by the National Natural Science Foundation of China (21173020, 21473008).

国家自然科学基金(21173020, 21473008)资助项目

(C) Editorial office of Acta Physico-Chimica Sinica 
theory is one of the important methods beyond the HartreeFock approximation. It combines the static and dynamic correlation effects into one single framework and provides versatile ways to describe the electronic structures of atomic and molecular systems. There are many research works on this field. ${ }^{11-40}$ To list just a few, there are Hylleraas variational perturbation theory by Cave and Davidson, ${ }^{11}$ CASPT2 and CASPT $3,{ }^{12}$ multireference Møller-Plesset perturbation theory of Hirao, ${ }^{13,14}$ multireference open-shell perturbation theory of Kozlowski and Davidson, ${ }^{15,16}$ the second order generalized van Vleck perturbation theory of Hoffmann et al. ${ }^{17,19}$ the state-specific multireference perturbation theory of Mukherjee et al., ${ }^{18}$ the configuration-based multireference second order perturbation theory of Wen et al. ${ }^{20,36}$, the $n$-electron valence state perturbation theory of Angeli et al., ${ }^{21,22}$ the multireference perturbation theory of Chen et al., ${ }^{23}$ the multiconfiguration perturbation theory of Surján et al., ${ }^{24,25,32}$ the valence bond perturbation theory of $\mathrm{Wu}$ et al., ${ }^{29,40}$ a spin adapted size extensive state specific multireference perturbation theory of Liu et al., ${ }^{33,34}$ the orbitally invariant multireference perturbation theory of Chen and Hoffmann, ${ }^{35}$ the block correlated perturbation theory of Xu and $\mathrm{Li}^{3},{ }^{37}$ the size extensive multireference perturbation theory of Chen and Fan, ${ }^{38}$ and SDS-MS-MRPT2 by Liu and Hoffmann. ${ }^{39}$ In spite of substantial works on the perturbation theory as shown above, their applications to electron affinity problems are not as many as one may expect.

In this study, we will compute the electron affinities of $\mathrm{F}, \mathrm{Cl}$, $\mathrm{CN}, \mathrm{OH}, \mathrm{SH}, \mathrm{CH}_{2}$, and $\mathrm{NH}_{2}$ with the second order multireference perturbation theory. ${ }^{23}$ Comparisons with the complete active space self-consistent field (CASSCF), ${ }^{41}$ CASPT $2,{ }^{12}$ the coupled cluster with single and double excitations (CCSD), ${ }^{42-45}$ CCSD plus the perturbation correction of triple excitations $(\operatorname{CCSD}(\mathrm{T})),{ }^{46}$ and density functional theories such as B3LYP,${ }^{47-49}$ X3LYP $,{ }^{50} \mathrm{M} 06,{ }^{51} \mathrm{HTCH},{ }^{52} \mathrm{TPSS},{ }^{53} \mathrm{~B} 97 \mathrm{D} 3,{ }^{54}$ mPW2PLYP,${ }^{55}$ and B2PLYP,${ }^{56}$ will be made to show their different performances. Especially, the effects of basis sets and size of the reference spaces on EA will be investigated and discussed in details.

\section{Computational method}

The second and third order multireference perturbation expressions can be written as follows ${ }^{1,23}$

$$
\begin{aligned}
E_{p}= & \varepsilon_{p}^{(0)}+\sum_{i, j \leq n} \sum_{a>n} \frac{u_{p}^{(0)}(i) H_{i a} H_{a j} u_{p}^{(0)}(j)}{\varepsilon_{p}^{(0)}-H_{a a}} \lambda^{2}+ \\
& \sum_{i, j \leq n} \sum_{\substack{a, b>n \\
a \neq b}} \frac{u_{p}^{(0)}(i) H_{i a} H_{a b} H_{b j} u_{p}^{(0)}(j)}{\left(\varepsilon_{p}^{(0)}-H_{a a}\right)\left(\varepsilon_{p}^{(0)}-H_{b b}\right)} \lambda^{3}+\cdots
\end{aligned}
$$

where $\varepsilon_{p}^{(0)}$ is the $p$-th eigenvalue and $u_{p}^{(0)}(i)$ is the $i$-th component of the corresponding $p$-th eigenvector in the reference space. The dimension of the reference space is $n . H_{i j}$ is the Hamiltonian matrix element with respect to the $i$-th and $j$-th configuration functions. $\lambda$ is a perturbation parameter and is set equal to unity for the final energy $E_{p}$. For an efficient implementation, Eq.(1) can be further expressed as

$$
\begin{aligned}
E_{p}= & \varepsilon_{p}^{(0)}+\sum_{a>n} \frac{\bar{H}_{p a} \bar{H}_{a p}}{\varepsilon_{p}^{(0)}-H_{a a}} \lambda^{2}+ \\
& \sum_{a>n} \sum_{\substack{b>n \\
a \neq b}} \frac{\bar{H}_{p a} H_{a b} \bar{H}_{b p}}{\left(\varepsilon_{p}^{(0)}-H_{a a}\right)\left(\varepsilon_{p}^{(0)}-H_{b b}\right)} \lambda^{3}+\cdots
\end{aligned}
$$

with $H_{p a}$ defined as

$$
\bar{H}_{p a}=\sum_{i=1}^{n} u_{p}^{(0)}(i) H_{i a}
$$

Eq.(2) is to some extent formally similar to the single reference perturbation expressions. ${ }^{1,23}$ But the key differences lie in the expression of $\bar{H}_{p a}$ to which not only the $p$-th state but also other states within the reference space have contributions to the energy $E_{p}$.

The electron affinities of $\mathrm{F}, \mathrm{Cl}, \mathrm{OH}, \mathrm{CN}, \mathrm{SH}, \mathrm{CH}_{2}$, and $\mathrm{NH}_{2}$ are calculated with the above second order multireference perturbation theory (MRPT2). Different basis sets with varieties of levels of theoretical methods have been exploited to calculate the electron affinity in literature. In order to compare the performance of different methods conveniently, the system basis sets, Dunning's correlation consistent basis functions, ${ }^{57,58} \mathrm{cc}-$ pVDZ, cc-pVTZ, aug-cc-pVDZ, and aug-cc-pVTZ are used for all theoretical approaches in the present work. CASSCF wave function is chosen as the zeroth order wavefucntion in MRPT2 and is calculated with GAMESS. ${ }^{59} \operatorname{CAS}(N, M)$ means that the configuration space is constructed with $N$ electrons distributed among $M$ orbitals in all possible ways. Calculations with CCSD, CCSD(T), B3LYP, X3LYP, M06, HTCH, TPSS, B97D3, mPW2PLYP, and B2PLYP are carried out with Gaussian program. ${ }^{60}$ Calculations with CASPT2 are carried out with MOLPRO. ${ }^{61}$

\section{Results and discussion}

\subsection{Electron affinities of $\mathrm{F}$ and $\mathrm{Cl}$}

There are many theoretical works on the electron affinity (EA) of F. Here only some representative works are discussed. They are the fourth order Møller-Plesset perturbation theory (MP4) and the coupled cluster theory, ${ }^{62}$ Gaussian-1 theory, ${ }^{63}$ Gaussian-2 theory, ${ }^{65}$ BLYP density functional theory, ${ }^{66}$ one electron propagator, ${ }^{67,68}$ and the multireference coupled cluster theory. ${ }^{69}$ In comparison with the EA value of $3.65 \mathrm{eV}$ calculated with MP4, ${ }^{62}$ the coupled cluster result $(3.37 \mathrm{eV})$ is much close to the experimental result of $3.401 \mathrm{eV} .{ }^{64}$ The theoretical estimation of Pople et al. ${ }^{65}$ for the affinity agrees perfectly with experiment, but has been obtained by assuming the additivity of the energy contributions arising from different basis set extensions, which introduces an approximation. The EA values $\left(3.550 \mathrm{eV}^{67}\right.$ and $3.538 \mathrm{eV}^{68}$ ) calculated with one electron propagator theories are overestimated. The results calculated with the multireference coupled cluster theory at the basis level of aug-cc-pVDZ, aug-cc-pVTZ, and aug-cc-pVQZ are 3.2378, 3.4014 , and $3.4986 \mathrm{eV}$, respectively. ${ }^{69}$ These results are presented at the bottom of Table 1 for the convenience of comparison. 
Table 1 Electron affinities (EA) of F calculated with CASSCF, CASPT2, MRPT2, CCSD, CCSD(T), B3LYP, X3LYP, M06, HCTH, TPSS, B97D3, mPW2PLYP, and B2PLYP methods

\begin{tabular}{|c|c|c|c|c|}
\hline Basis set & Method & $E(\mathrm{~F}) /($ a.u. $)$ & $E\left(\mathrm{~F}^{-}\right) /($a.u. $)$ & $\mathrm{EA} / \mathrm{eV}$ \\
\hline \multirow[t]{13}{*}{ cc-pVDZ } & CASSCF & -99.429375 & -99.451621 & 0.605 \\
\hline & CASPT2 & -99.520037 & -99.551177 & 0.847 \\
\hline & MRPT2 & -99.533222 & -99.566845 & 0.915 \\
\hline & CCSD & -99.526690 & -99.557846 & 0.848 \\
\hline & $\operatorname{CCSD}(\mathrm{T})$ & -99.527574 & -99.558453 & 0.840 \\
\hline & B3LYP & -99.726600 & -99.769792 & 1.175 \\
\hline & X3LYP & -99.698900 & -99.739480 & 1.104 \\
\hline & M06 & -99.695328 & -99.747367 & 1.416 \\
\hline & HCTH & -99.694183 & -99.745557 & 1.398 \\
\hline & TPSS & -99.731401 & -99.769522 & 1.037 \\
\hline & B97D3 & -99.675702 & -99.720999 & 1.233 \\
\hline & mPW2PLYP & -99.662265 & -99.700045 & 1.028 \\
\hline & B2PLYP & -99.660923 & -99.699124 & 1.040 \\
\hline \multirow[t]{13}{*}{ cc-pVTZ } & CASSCF & -99.462487 & -99.522939 & 1.645 \\
\hline & CASPT2 & -99.608776 & -99.685635 & 2.091 \\
\hline & MRPT2 & -99.629778 & -99.713493 & 2.278 \\
\hline & CCSD & -99.616771 & -99.692820 & 2.069 \\
\hline & $\operatorname{CCSD}(\mathrm{T})$ & -99.620361 & -99.698384 & 2.123 \\
\hline & B3LYP & -99.762866 & -99.850177 & 2.376 \\
\hline & X3LYP & -99.735270 & -99.819880 & 2.302 \\
\hline & M06 & -99.722897 & -99.809492 & 2.356 \\
\hline & НCTH & -99.729265 & -99.822278 & 2.531 \\
\hline & TPSS & -99.766051 & -99.848561 & 2.245 \\
\hline & B97D3 & -99.711790 & -99.799662 & 2.391 \\
\hline & mPW2PLYP & -99.712213 & -99.793720 & 2.218 \\
\hline & B2PLYP & -99.712143 & -99.794945 & 2.253 \\
\hline \multirow[t]{13}{*}{ aug-cc-pVDZ } & CASSCF & -99.434409 & -99.534289 & 2.718 \\
\hline & CASPT2 & -99.540953 & -99.657753 & 3.178 \\
\hline & MRPT2 & -99.555382 & -99.682400 & 3.456 \\
\hline & CCSD & -99.547749 & -99.662690 & 3.128 \\
\hline & $\operatorname{CCSD}(\mathrm{T})$ & -99.550069 & -99.668634 & 3.226 \\
\hline & B3LYP & -99.739496 & -99.870373 & 3.562 \\
\hline & X3LYP & -99.711950 & -99.840520 & 3.498 \\
\hline & M06 & -99.706058 & -99.833058 & 3.456 \\
\hline & $\mathrm{HCTH}$ & -99.707343 & -99.849552 & 3.870 \\
\hline & TPSS & -99.743769 & -99.870716 & 3.454 \\
\hline & B97D3 & -99.688316 & -99.822075 & 3.640 \\
\hline & mPW2PLYP & -99.676727 & -99.801479 & 3.395 \\
\hline & B2PLYP & -99.675638 & -99.802108 & 3.441 \\
\hline Exp. $^{64}$ & & & & 3.401 \\
\hline Adamowicz et al..$^{62}$ & & & & $3.653,3.373^{\mathrm{a}}$ \\
\hline Pople et al. ${ }^{63}$ & & & & 3.46 \\
\hline Curtiss et al. ${ }^{65}$ & & & & 3.48 \\
\hline Gill et al. ${ }^{66}$ & & & & 3.42 \\
\hline Yeager et al. ${ }^{67}$ & & & & 3.550 \\
\hline Ortiz $^{68}$ & & & & 3.538 \\
\hline Jana et al..$^{69}$ & & & & 3.372 \\
\hline
\end{tabular}

a 3.653 and $3.373 \mathrm{eV}$ were calculated respectively with the fourth order perturbation theory and coupled cluster theory. The complete active spaces for $\mathrm{F}$ and $\mathrm{F}^{-}$are $\mathrm{CAS}(5,7)$ and $\mathrm{CAS}(6,7)$, respectively. 
In this study, the complete active spaces for $\mathrm{F}$ and $\mathrm{F}^{-}$are $\operatorname{CAS}(5,7)$ and $\operatorname{CAS}(6,7)$, respectively. The electron affinities calculated with CASSCF, CASPT2, MRPT2, CCSD, CCSD(T), B3LYP, X3LYP, M06, HTCH, TPSS, B97D3, mPW2PLYP, and B2PLYP are listed in Table 1. As can be seen from the table, the EA values calculated with the cc-pVDZ basis set are far away from the experimental value of $3.401 \mathrm{eV}^{64}$ in spite of various theoretical methods used. As the basis set is increased to cc-pVTZ, the number of the bases is changed from 14 to 30 . Yet the computed EAs are still not so close to the experimental value although they are improved substantially. However, when aug-cc-pVDZ is considered, the theoretical EA values computed with MRPT2, CCSD, CCSD(T), and CASPT2 become much closer to the experimental result in spite of the fact that the number of the bases in the aug-cc-pVDZ is less than the number of the bases in the cc-pVTZ. This demonstrates the important role of diffuse functions in obtaining accurate theoretical EA values. Among the wavefunction methods, the best agreement with the experimental EA value of $3.401 \mathrm{eV}^{64}$ has been achieved by MRPT2/aug-cc-pVDZ with the difference less than $0.100 \mathrm{eV}$. CASPT2 results are less accurate than the results of MRPT2 and $\operatorname{CCSD}(\mathrm{T})$ but are slightly better than the results of CCSD for this problem at the level of aug-cc-pVDZ. However, all CASSCF results are not satisfactory and their differences with the experimental value of $3.401 \mathrm{eV}^{64}$ are still as large as about $0.700 \mathrm{eV}$ even at the level of aug-cc-pVDZ. The accuracies of M06, TPSS, mPW2PLYP, and B2PLYP are comparable to the accuracy of MRPT2 and are better than the accuracies of B3LYP, X3LYP, HTCH, and B97D3. In comparison with the B3LYP results, Gill et al.$^{66}$ obtained an accurate EA value of $3.42 \mathrm{eV}$ for F with BLYP/6-311+G(2df, $p)$ as shown at the bottom of Table 1, but results of BLYP are not stable and case dependent. This is the nature of density functional theory as will be shown later.

Because of similarity of the valence electron structure between $\mathrm{Cl}$ and $\mathrm{F}$, the complete active spaces for $\mathrm{Cl}$ and $\mathrm{Cl}^{-}$are also $\mathrm{CAS}(5,7)$ and $\mathrm{CAS}(6,7)$, the same as for $\mathrm{F}$ and $\mathrm{F}^{-}$, respectively. The calculated electron affinities of $\mathrm{Cl}$ with various methods are listed in Table 2. It can be seen from the table that the best EA value is $3.601 \mathrm{eV}$ obtained with MRPT2/aug-ccpVDZ, which is comparable to the accuracy achieved with the renormalized electron propagator method at the level of aug-ccpVTZ by Ortiz ${ }^{68}$ as shown at the bottom of the table. The EA value of $3.617 \mathrm{eV}$ with a model potential-quantum Monte Carlo study $^{70}$ is in very good agreement with experiment, ${ }^{71}$ yet its error is as high as $\pm 0.198 \mathrm{eV}$ because of stochastic nature of Monte Carlo method. Among the density functional theories, the accuracies of mPW2PLYP and B2PLYP are comparable to the accuracy of MRPT2. Their performances are better than that of $\operatorname{CCSD}, \operatorname{CCSD}(\mathrm{T}), \mathrm{CASPT} 2$, and other density functional methods presented in Table 2. The accuracy of CASSCF results at different levels of basis sets are still inferior to the ac- curacies of other methods listed in the table indicating the important role played by the dynamic correlation.

\subsection{Electron affinities of $\mathrm{OH}$ and $\mathrm{SH}$}

The experimental equilibrium bond lengths of $\mathrm{OH}$ and $\mathrm{OH}^{-} 72$ are used for electron affinity calculation. $\mathrm{OH}$ is an isoelectronic system of F. However, its electronic structure seems more complicated than the latter. We first explore the complete active space $\mathrm{CAS}(5,6)$ and $\mathrm{CAS}(6,6)$ for $\mathrm{OH}$ and $\mathrm{OH}^{-}$separately. As shown at the top of Table 3, except the positive EA value calculated with MRPT2/cc-pVDZ, all other methods, CASSCF, CASPT2, CCSD, CCSD(T), B3LYP, X3LYP, M06, HTCH, TPSS, B97D3, mPW2PLYP, and B2PLYP at the same basis, predict negative EA values indicating that $\mathrm{OH}^{-}$is not stable, which is however not in agreement with the experimental observation. ${ }^{73}$ Furthermore, CASSCF wavefunction at cc-pVTZ basis still produces a negative EA value. These calculations demonstrate the difficulty in obtaining the electron affinity of $\mathrm{OH}$. As the basis set is extended to aug-cc-pVDZ, EAs calculated with various methods except CASSCF are improved substantially. However, the CASPT2, CCSD, and CCSD(T) results still underestimate the experimental value while the MRPT2 result overestimates it. As the basis is extended further to aug-cc-pVTZ, the EAs calculated with CASPT2, CCSD, and $\operatorname{CCSD}(\mathrm{T})$ are improved as shown in the lower part of Table 3. However, the change of the basis set almost has no effect on the results of CASSCF and MRPT2, which means that a large static correlation may be needed for a further improvement on their EA values. Therefore, the complete active spaces are enlarged from $\operatorname{CAS}(5,6)$ and $\operatorname{CAS}(6,6)$ to $\operatorname{CAS}(7,7)$ and $\operatorname{CAS}(8,7)$ for $\mathrm{OH}$ and $\mathrm{OH}^{-}$, respectively. The corresponding results are listed at the lower part of Table 3. The MRPT2 result of $1.91 \mathrm{eV}$ becomes better than the result of $2.044 \mathrm{eV}$ obtained with a small complete active space and agrees very well with the experimental value of $1.83 \mathrm{eV}^{73}$ to within $0.10 \mathrm{eV}$. However, the CASSCF and CASPT2 results are still not satisfactory. The EA value of $1.78 \mathrm{eV}$ calculated with MP4 and a large basis 6$311++G(3 d f, 3 p d)$ is reported by Frenking and $\mathrm{Koch}^{75}$ and are in very good agreement with the experimental value of $1.83 \mathrm{eV}$. Though partial quadruple excitations in MP4 have been included in CASPT2, yet it seems that these excitations are still not enough to achieve an accurate result with CASPT2.

Among the density functional methods, the results of B3LYP, X3LYP, B97D3, mPW2PLYP, and B2PLYP at the level of aug-cc-pVTZ are in very close agreement with the experimental value of $1.83 \mathrm{eV} .{ }^{73}$ Similar results of other density function theories like BLYP ${ }^{66,74}$ are listed at the bottom of Table $3{ }^{65-68,73-75}$ As can be seen from the results of Tables $1-3$, density functional theories as a whole are reliable approaches at a very large basis set though the performance of each individual functional is different from each other and is dependent on the system studied. 
Table 2 Electron affinities of Cl calculated with CASSCF, CASPT2, MRPT2, CCSD, CCSD(T), B3LYP, X3LYP, M06, HCTH, TPSS, B97D3, mPW2PLYP, and B2PLYP methods

\begin{tabular}{|c|c|c|c|c|}
\hline Basis set & Method & $E(\mathrm{Cl}) /($ a.u. $)$ & $E\left(\mathrm{Cl}^{-}\right) /$(a.u. $)$ & $\mathrm{EA} / \mathrm{eV}$ \\
\hline \multirow[t]{13}{*}{ cc-pVDZ } & CASSCF & -459.487049 & -459.573113 & 2.342 \\
\hline & CASPT2 & -459.586003 & -459.676216 & 2.455 \\
\hline & MRPT2 & -459.619926 & -459.711673 & 2.497 \\
\hline & CCSD & -459.597739 & -459.688435 & 2.468 \\
\hline & $\operatorname{CCSD}(\mathrm{T})$ & -459.598893 & -459.689586 & 2.468 \\
\hline & B3LYP & -460.158464 & -460.266576 & 2.942 \\
\hline & X3LYP & -460.109200 & -460.215200 & 2.884 \\
\hline & M06 & -460.124069 & -460.237609 & 3.090 \\
\hline & НСТН & -460.206465 & -460.317992 & 3.035 \\
\hline & TPSS & -460.160420 & -460.267922 & 2.925 \\
\hline & B97D3 & -460.169267 & -460.274525 & 2.864 \\
\hline & mPW2PLYP & -460.013773 & -460.115653 & 2.772 \\
\hline & B2PLYP & -459.999667 & -460.101273 & 2.765 \\
\hline \multirow[t]{13}{*}{ cc-pVTZ } & CASSCF & -459.508674 & -459.599707 & 2.477 \\
\hline & CASPT2 & -459.644878 & -459.757529 & 3.065 \\
\hline & MRPT2 & -459.713019 & -459.828584 & 3.145 \\
\hline & CCSD & -459.666282 & -459.778021 & 3.041 \\
\hline & $\operatorname{CCSD}(\mathrm{T})$ & -459.671808 & -459.785130 & 3.084 \\
\hline & B3LYP & -460.174662 & -460.297536 & 3.344 \\
\hline & X3LYP & -460.125500 & -460.246300 & 3.288 \\
\hline & M06 & -460.135280 & -460.258112 & 3.342 \\
\hline & HCTH & -460.221673 & -460.345835 & 3.379 \\
\hline & TPSS & -460.176774 & -460.297527 & 3.286 \\
\hline & B97D3 & -460.185880 & -460.305288 & 3.249 \\
\hline & mPW2PLYP & -460.042919 & -460.161176 & 3.218 \\
\hline & B2PLYP & -460.030020 & -460.148400 & 3.221 \\
\hline \multirow[t]{13}{*}{ aug-cc-pVDZ } & CASSCF & -459.489136 & -459.600495 & 3.030 \\
\hline & CASPT2 & -459.598382 & -459.720792 & 3.331 \\
\hline & MRPT2 & -459.633432 & -459.765752 & 3.601 \\
\hline & CCSD & -459.609931 & -459.734186 & 3.381 \\
\hline & $\operatorname{CCSD}(\mathrm{T})$ & -459.612222 & -459.738302 & 3.431 \\
\hline & B3LYP & -460.161471 & -460.298160 & 3.720 \\
\hline & X3LYP & -460.112400 & -460.247400 & 3.674 \\
\hline & M06 & -460.126265 & -460.264790 & 3.769 \\
\hline & HCTH & -460.209578 & -460.349847 & 3.817 \\
\hline & TPSS & -460.162675 & -460.296231 & 3.634 \\
\hline & B97D3 & -460.172078 & -460.305836 & 3.640 \\
\hline & mPW2PLYP & -460.019400 & -460.151471 & 3.594 \\
\hline & B2PLYP & -460.005489 & -460.137444 & 3.591 \\
\hline Exp. $^{71}$ & & & & 3.615 \\
\hline Curtiss et al..$^{65}$ & & & & 3.60 \\
\hline Ortiz $^{68}$ & & & & 3.613 \\
\hline Yoshida et al. ${ }^{70}$ & & & & 3.617 \\
\hline
\end{tabular}


Table 3 Electron affinities of OH calculated with CASSCF, CASPT2, MRPT2, CCSD, CCSD(T), B3LYP, X3LYP, M06, HCTH, TPSS, B97D3, mPW2PLYP, and B2PLYP methods

\begin{tabular}{|c|c|c|c|c|}
\hline Basis set & Method & $E(\mathrm{OH}) /($ a.u. $)$ & $E\left(\mathrm{OH}^{-}\right) /($a.u. $)$ & $\mathrm{EA} / \mathrm{eV}$ \\
\hline \multirow[t]{13}{*}{ cc-pVDZ } & CASSCF* & -75.442468 & -75.360601 & -2.228 \\
\hline & CASPT2* & -75.549612 & -75.527012 & -0.615 \\
\hline & MRPT2* & -75.566923 & -75.571652 & 0.129 \\
\hline & CCSD & -75.557537 & -75.532992 & -0.668 \\
\hline & $\operatorname{CCSD}(\mathrm{T})$ & -75.559266 & -75.535270 & -0.653 \\
\hline & B3LYP & -75.731924 & -75.721026 & -0.297 \\
\hline & X3LYP & -75.704780 & -75.691470 & -0.362 \\
\hline & M06 & -75.695447 & -75.689386 & -0.165 \\
\hline & $\mathrm{HTCH}$ & -75.711443 & -75.706846 & -0.125 \\
\hline & TPSS & -75.738045 & -75.723111 & -0.406 \\
\hline & B97D3 & -75.688642 & -75.678700 & -0.271 \\
\hline & mPW2PLYP & -75.669485 & -75.652901 & -0.451 \\
\hline & B2PLYP & -75.669241 & -75.653042 & -0.441 \\
\hline \multirow[t]{13}{*}{ cc-pVTZ } & CASSCF* & -75.469812 & -75.413562 & -1.531 \\
\hline & CASPT2* & -75.626530 & -75.647583 & 0.573 \\
\hline & MRPT2* & -75.647369 & -75.698814 & 1.400 \\
\hline & CCSD & -75.632632 & -75.649877 & 0.469 \\
\hline & $\operatorname{CCSD}(\mathrm{T})$ & -75.637722 & -75.657692 & 0.543 \\
\hline & B3LYP & -75.764105 & -75.790402 & 0.716 \\
\hline & X3LYP & -75.737070 & -75.76086 & 0.647 \\
\hline & M06 & -75.721466 & -75.746763 & 0.688 \\
\hline & HCTH & -75.742230 & -75.772215 & 0.816 \\
\hline & TPSS & -75.768223 & -75.790173 & 0.597 \\
\hline & B97D3 & -75.720105 & -75.746275 & 0.712 \\
\hline & mPW2PLYP & -75.712958 & -75.734889 & 0.597 \\
\hline & B2PLYP & -75.713849 & -75.736983 & 0.629 \\
\hline \multirow[t]{13}{*}{ aug-cc-pVDZ } & CASSCF* & -75.454418 & -75.457839 & 0.093 \\
\hline & CASPT2* & -75.573022 & -75.628419 & 1.507 \\
\hline & MRPT2* & -75.590455 & -75.665554 & 2.044 \\
\hline & CCSD & -75.580634 & -75.635832 & 1.502 \\
\hline & $\operatorname{CCSD}(\mathrm{T})$ & -75.583992 & -75.643882 & 1.630 \\
\hline & B3LYP & -75.748921 & -75.816934 & 1.851 \\
\hline & X3LYP & -75.722000 & -75.78785 & 1.792 \\
\hline & M06 & -75.710374 & -75.773186 & 1.709 \\
\hline & HCTH & -75.728804 & -75.806155 & 2.105 \\
\hline & TPSS & -75.754002 & -75.817795 & 1.736 \\
\hline & B97D3 & -75.705246 & -75.775367 & 1.908 \\
\hline & mPW2PLYP & -75.687914 & -75.752148 & 1.748 \\
\hline & B2PLYP & -75.687852 & -75.753854 & 1.796 \\
\hline \multirow[t]{10}{*}{ aug-cc-pVTZ } & CASSCF* & -75.472903 & -75.475076 & 0.059 \\
\hline & CASPT2* & -75.632772 & -75.692257 & 1.619 \\
\hline & MRPT2* & -75.650849 & -75.727345 & 2.082 \\
\hline & CCSD & -75.639697 & -75.696999 & 1.559 \\
\hline & $\operatorname{CCSD}(\mathrm{T})$ & -75.645575 & -75.709421 & 1.737 \\
\hline & B3LYP & -75.768563 & -75.836237 & 1.841 \\
\hline & X3LYP & -75.741650 & -75.807110 & 1.781 \\
\hline & M06 & -75.724825 & -75.787695 & 1.711 \\
\hline & НCTH & -75.747830 & -75.824679 & 2.091 \\
\hline & TPSS & -75.772660 & -75.835850 & 1.719 \\
\hline
\end{tabular}


continued Table 3

\begin{tabular}{|c|c|c|c|c|}
\hline Basis set & Method & $E(\mathrm{OH}) /($ a.u. $)$ & $E\left(\mathrm{OH}^{-}\right) /($a.u. $)$ & $\mathrm{EA} / \mathrm{eV}$ \\
\hline \multirow{6}{*}{ aug-cc-pVDZ } & B97D3 & -75.724778 & -75.794180 & 1.886 \\
\hline & mPW2PLYP & -75.718333 & -75.783504 & 1.773 \\
\hline & B2PLYP & -75.719262 & -75.786403 & 1.827 \\
\hline & CASSCF** & -75.476469 & -75.481469 & 0.136 \\
\hline & CASPT $2 * *$ & -75.631985 & -75.691580 & 1.622 \\
\hline & MRPT2** & -75.587459 & -75.657657 & 1.910 \\
\hline Exp. $^{73}$ & & & & 1.83 \\
\hline Curtiss et al. ${ }^{65}$ & & & & 1.87 \\
\hline Gill et al. ${ }^{66}$ & & & & 1.72 \\
\hline Yeager et al..$^{67}$ & & & & 1.68 \\
\hline Ortiz $^{68}$ & & & & 1.85 \\
\hline Proft et al.$^{74}$ & & & & 1.85 \\
\hline Frenking ${ }^{75}$ & & & & 1.78 \\
\hline
\end{tabular}

*The complete active spaces for $\mathrm{OH}$ and $\mathrm{OH}^{-}$are $\mathrm{CAS}(5,6)$ and $\mathrm{CAS}(6,6)$, respectively.

**The complete active spaces for $\mathrm{OH}$ and $\mathrm{OH}^{-}$are $\mathrm{CAS}(7,7)$ and $\mathrm{CAS}(8,7)$, respectively.

The bond lengths of $\mathrm{SH}$ and $\mathrm{SH}^{-}$are 0.1338 and $0.1342 \mathrm{~nm},{ }^{68}$ respectively. They are optimized with the second-order MøllerPlesset perturbation theory at the level of $6-311++\mathrm{G}(d, p)$ basis. Electron affinities of SH calculated with CASSCF, CASPT2, MRPT2, CCSD, CCSD(T), B3LYP, X3LYP, M06, HTCH, TPSS, B97D3, mPW2PLYP, and B2PLYP are presented in Table 4. In comparison with the results of $\mathrm{OH}$ in Table 3, EAs of $\mathrm{SH}$ are all positive at the level of cc-pVDZ basis, which indicates that EAs of SH are easier to be calculated. At the level of aug-cc-pVDZ, the results of MRPT2, B3LYP, X3LYP, M06, TPSS, B97D3, mPW2PLYP, and B2PLYP are very close to the experimental value of $2.319 \mathrm{eV} .^{76}$ As the basis set is extended to aug-cc-pVTZ, the $\operatorname{CCSD}(\mathrm{T})$ result is also improved and is in close agreement with the experimental result. But the CASPT2 and CCSD results are still about $0.2 \mathrm{eV}$ less than the experimental value. The performance of CASSCF even with the augcc-pVTZ basis is still much inferior to the performances of all other methods listed in the table.

\subsection{Electron affinity of $\mathrm{CN}$}

The experimental equilibrium bond lengths of $\mathrm{CN}$ and $\mathrm{CN}$ are separately 0.1172 and $0.1177 \mathrm{~nm}^{72}$ and are exploited for computation of the electron affinity. The complete active spaces for $\mathrm{CN}$ and $\mathrm{CN}^{-}$are $\mathrm{CAS}(7,7)$ and $\mathrm{CAS}(8,7)$, respectively. The results calculated with various theoretical methods are presented in Table 5. In comparison with the experimental EA value of $3.82 \mathrm{eV},{ }^{77}$ the performances of MRPT2, HCTH, M06, and B2PLYP with aug-cc-pVDZ are better than those of other theoretical approaches presented in the table.

The previous studies on the electron affinity of $\mathrm{CN}$ are listed at the bottom of the table for the purpose of comparison. Among them, the results of Gaussian-2 theory by Pople et al. ${ }^{65}$ and one electron propagator method by Ortiz $^{68}$ are very close to the experimental value of $3.82 \mathrm{eV} .{ }^{77}$ However, the BLYP density functional theory result by Gill et al. ${ }^{66}$ is inferior to the BLYP result by Proft and Geerlings ${ }^{74}$ due to their different basis sets used in the study. The EA value predicted by Yeager et al. ${ }^{67}$ with the electron propagator method is also not satisfactory.

\subsection{Electron affinities of $\mathrm{CH}_{2}$ and $\mathrm{NH}_{2}$}

The geometrical parameters of $\mathrm{CH}_{2}, \mathrm{CH}_{2}^{-}, \mathrm{NH}_{2}$, and $\mathrm{NH}_{2}^{-}$ are taken from references, ${ }^{68,78}$ respectively. Electron affinities of $\mathrm{CH}_{2}$ and $\mathrm{NH}_{2}$ are presented in Tables 6 and 7. ${ }^{65-68,74,78-82}$ As can be seen from these two tables, most of EA values of $\mathrm{CH}_{2}$ and $\mathrm{NH}_{2}$ are negative at the basis levels of cc-pVDZ and cc-pVTZ. Even though the EAs of $\mathrm{CH}_{2}$ calculated with MRPT2 and density functional methods at the level of cc-pVTZ are positive, yet their absolute errors with the experimental value of $0.652 \mathrm{eV}^{79}$ are still large. These results demonstrate that $\mathrm{CH}_{2}$ and $\mathrm{NH}_{2}$ are more difficult to describe than $\mathrm{OH}$ as discussed in Section 3.2. As the basis is extended to aug-cc-pVDZ, the EAs of $\mathrm{CH}_{2}$ calculated with all theoretical approaches are improved substantially and are listed in the lower part of Table 6. The MRPT2 result of $\mathrm{CH}_{2}$ is in very close agreement with the experimental value with the absolute error less than $0.04 \mathrm{eV} .{ }^{79}$ On the other hand, the EA of $\mathrm{NH}_{2}$ calculated with MRPT2/aug-cc-pVDZ is still not satisfactory, which is similar to the situation of $\mathrm{OH}$ in Table 3. Therefore, the complete active spaces of $\mathrm{NH}_{2}$ and $\mathrm{NH}_{2}^{-}$are enlarged from $\operatorname{CAS}(6,6)$ and $\operatorname{CAS}(7,6)$ to $\operatorname{CAS}(7,7)$ and CAS $(8,7)$, respectively. As can be seen from Table 7 , the effect of the size of the complete active space on EA values is very significant. The absolute error of the MRPT2 result is only $0.005 \mathrm{eV}$ in comparison with the experimental value of 0.77 $\mathrm{eV}{ }^{81}$ The performances of CASSCF and CASPT2 are still not satisfactory.

Similar to the results of OH in Table 3, B3LYP, X3LYP, and B97D3 demonstrate very good performances for both $\mathrm{CH}_{2}$ and $\mathrm{NH}_{2}$. The EA values of $\mathrm{CH}_{2}$ calculated with $\mathrm{HCTH}$, $\mathrm{mPW} 2 \mathrm{PLYP}$, and B2PLYP at the level of aug-cc-pVDZ is also in good agreement with the experimental result. ${ }^{79}$ It is worthy to mention that good accuracies have been achieved with Gaussian2 theory ${ }^{65}$, density functional theory, ${ }^{66,74}$ one electron propagator method, ${ }^{68}$ and the multireference configuration interaction method, ${ }^{80,82}$ as listed at the bottoms of Tables 6 and 7 . 
Table 4 Electron affinities of SH calculated with CASSCF, CASPT2, MRPT2, CCSD, CCSD(T), B3LYP, X3LYP, M06, HCTH, TPSS, B97D3, mPW2PLYP, and B2PLYP methods

\begin{tabular}{|c|c|c|c|c|}
\hline Basis set & Method & $E(\mathrm{SH}) /($ a.u. $)$ & $E\left(\mathrm{SH}^{-}\right) /($a.u. $)$ & $\mathrm{EA} / \mathrm{eV}$ \\
\hline \multirow[t]{13}{*}{ cc-pVDZ } & CASSCF & -398.108697 & -398.128461 & 0.538 \\
\hline & CASPT2 & -398.210130 & -398.248650 & 1.048 \\
\hline & MRPT2 & -398.235440 & -398.282653 & 1.285 \\
\hline & CCSD & -398.222340 & -398.262482 & 1.092 \\
\hline & $\operatorname{CCSD}(\mathrm{T})$ & -398.224540 & -398.264982 & 1.100 \\
\hline & B3LYP & -398.762179 & -398.818561 & 1.534 \\
\hline & X3LYP & -398.713300 & -398.767600 & 1.478 \\
\hline & M06 & -398.724839 & -398.784399 & 1.621 \\
\hline & НCTH & -398.800444 & -398.859615 & 1.610 \\
\hline & TPSS & -398.764711 & -398.821182 & 1.537 \\
\hline & B97D3 & -398.758832 & -398.812701 & 1.466 \\
\hline & mPW2PLYP & -398.616067 & -398.666134 & 1.362 \\
\hline & B2PLYP & -398.603216 & -398.653117 & 1.358 \\
\hline \multirow[t]{13}{*}{ aug-cc-pVDZ } & CASSCF & -398.117909 & -398.154627 & 0.999 \\
\hline & CASPT2 & -398.222273 & -398.296418 & 2.018 \\
\hline & MRPT2 & -398.245210 & -398.330519 & 2.321 \\
\hline & CCSD & -398.234393 & -398.309921 & 2.055 \\
\hline & $\operatorname{CCSD}(\mathrm{T})$ & -398.237757 & -398.315668 & 2.120 \\
\hline & B3LYP & -398.766652 & -398.853388 & 2.360 \\
\hline & X3LYP & -398.717900 & -398.803000 & 2.316 \\
\hline & M06 & -398.728621 & -398.815648 & 2.368 \\
\hline & HCTH & -398.804985 & -398.894789 & 2.444 \\
\hline & TPSS & -398.768252 & -398.852163 & 2.283 \\
\hline & B97D3 & -398.763062 & -398.847519 & 2.298 \\
\hline & mPW2PLYP & -398.622755 & -398.705080 & 2.240 \\
\hline & B2PLYP & -398.610042 & -398.692367 & 2.240 \\
\hline \multirow[t]{13}{*}{ aug-cc-pVTZ } & CASSCF & -398.123164 & -398.167095 & 1.195 \\
\hline & CASPT2 & -398.270893 & -398.348337 & 2.107 \\
\hline & MRPT2 & -398.298175 & -398.383980 & 2.335 \\
\hline & CCSD & -398.284684 & -398.363169 & 2.136 \\
\hline & $\operatorname{CCSD}(\mathrm{T})$ & -398.291363 & -398.373493 & 2.235 \\
\hline & B3LYP & -398.781207 & -398.867099 & 2.337 \\
\hline & X3LYP & -398.732500 & -398.816700 & 2.292 \\
\hline & M06 & -398.739226 & -398.821966 & 2.251 \\
\hline & НСТН & -398.818271 & -398.907665 & 2.433 \\
\hline & TPSS & -398.783921 & -398.866747 & 2.254 \\
\hline & B97D3 & -398.778490 & -398.861567 & 2.261 \\
\hline & mPW2PLYP & -398.646459 & -398.729204 & 2.252 \\
\hline & B2PLYP & -398.634601 & -398.717551 & 2.257 \\
\hline Exp. $^{76}$ & & & & 2.319 \\
\hline Curtiss et al.$^{65}$ & & & & 2.30 \\
\hline Ortiz $^{68}$ & & & & 2.29 \\
\hline Proft et al..$^{74}$ & & & & 2.27 \\
\hline
\end{tabular}


Table 5 Electron affinity values for $\mathrm{CN}\left(X^{2} \Sigma^{+}\right)$calculated with CASSCF, CASPT2, MRPT2, CCSD, CCSD(T), B3LYP, X3LYP, M06, HCTH, TPSS, B97D3, mPW2PLYP, and B2PLYP methods

\begin{tabular}{|c|c|c|c|c|}
\hline Basis set & Method & $E(\mathrm{CN}) /($ a.u. $)$ & $E\left(\mathrm{CN}^{-}\right) /($a.u. $)$ & $\mathrm{EA} / \mathrm{eV}$ \\
\hline \multirow[t]{13}{*}{ cc-pVDZ } & CASSCF & -92.335867 & -92.413301 & 2.107 \\
\hline & CASPT2 & -92.473924 & -92.572488 & 2.682 \\
\hline & MRPT2 & -92.489766 & -92.597552 & 2.933 \\
\hline & CCSD & -92.476679 & -92.580602 & 2.828 \\
\hline & $\operatorname{CCSD}(\mathrm{T})$ & -92.489071 & -92.592053 & 2.802 \\
\hline & B3LYP & -92.719427 & -92.836492 & 3.186 \\
\hline & X3LYP & -92.680140 & -92.795650 & 3.143 \\
\hline & M06 & -92.656898 & -92.772010 & 3.132 \\
\hline & HCTH & -92.703971 & -92.811440 & 2.924 \\
\hline & TPSS & -92.742323 & -92.849176 & 2.908 \\
\hline & B97D3 & -92.665532 & -92.771210 & 2.876 \\
\hline & mPW2PLYP & -92.636027 & -92.748604 & 3.063 \\
\hline & B2PLYP & -92.638959 & -92.749682 & 3.013 \\
\hline \multirow[t]{13}{*}{ cc-pVTZ } & CASSCF & -92.357154 & -92.447637 & 2.462 \\
\hline & CASPT2 & -92.548498 & -92.670695 & 3.325 \\
\hline & MRPT2 & -92.565941 & -92.697747 & 3.587 \\
\hline & CCSD & -92.547224 & -92.675723 & 3.497 \\
\hline & $\operatorname{CCSD}(\mathrm{T})$ & -92.565704 & -92.694000 & 3.491 \\
\hline & B3LYP & -92.745622 & -92.882172 & 3.716 \\
\hline & X3LYP & -92.706420 & -92.841510 & 3.676 \\
\hline & M06 & -92.682730 & -92.812113 & 3.521 \\
\hline & HCTH & -92.724858 & -92.850691 & 3.424 \\
\hline & TPSS & -92.765545 & -92.890455 & 3.399 \\
\hline & B97D3 & -92.689034 & -92.813643 & 3.391 \\
\hline & mPW2PLYP & -92.675186 & -92.808240 & 3.621 \\
\hline & B2PLYP & -92.679296 & -92.810876 & 3.580 \\
\hline \multirow[t]{13}{*}{ aug-cc-pVDZ } & CASSCF & -92.339570 & -92.437903 & 2.676 \\
\hline & CASPT2 & -92.486413 & -92.616759 & 3.547 \\
\hline & MRPT2 & -92.498063 & -92.636016 & 3.754 \\
\hline & CCSD & -92.488563 & -92.624561 & 3.701 \\
\hline & $\operatorname{CCSD}(\mathrm{T})$ & -92.502297 & -92.639388 & 3.730 \\
\hline & B3LYP & -92.725050 & -92.873580 & 4.042 \\
\hline & X3LYP & -92.68593 & -92.833310 & 4.010 \\
\hline & M06 & -92.661954 & -92.804506 & 3.879 \\
\hline & $\mathrm{HCTH}$ & -92.709121 & -92.849447 & 3.818 \\
\hline & TPSS & -92.747030 & -92.882847 & 3.696 \\
\hline & B97D3 & -92.670371 & -92.807576 & 3.734 \\
\hline & mPW2PLYP & -92.643524 & -92.788060 & 3.933 \\
\hline & B2PLYP & -92.646497 & -92.789344 & 3.887 \\
\hline Exp. $^{77}$ & & & & 3.82 \\
\hline Curtiss et al..$^{65}$ & & & & 3.97 \\
\hline Gill et al. ${ }^{66}$ & & & & 4.58 \\
\hline Yeager et al. ${ }^{67}$ & & & & 4.13 \\
\hline Ortiz $^{68}$ & & & & 3.83 \\
\hline Proft et al..$^{74}$ & & & & 3.75 \\
\hline
\end{tabular}


Table 6 Electron affinities for $\mathrm{CH}_{2}\left(X^{3} B_{1}\right)$ calculated with CASSCF, CASPT2, MRPT2, CCSD, CCSD(T), B3LYP, X3LYP, M06, HCTH, TPSS, B97D3, mPW2PLYP, and B2PLYP methods

\begin{tabular}{|c|c|c|c|c|}
\hline Basis set & Method & $E\left(\mathrm{CH}_{2}\right) /($ a.u. $)$ & $E\left(\mathrm{CH}_{2}^{-}\right) /($a.u. $)$ & $\mathrm{EA} / \mathrm{eV}$ \\
\hline \multirow[t]{13}{*}{ cc-pVDZ } & CASSCF & -38.959891 & -38.899932 & -1.632 \\
\hline & CASPT2 & -39.032521 & -39.003184 & -0.798 \\
\hline & MRPT2 & -39.044488 & -39.026679 & -0.485 \\
\hline & CCSD & -39.039718 & -39.014525 & -0.686 \\
\hline & $\operatorname{CCSD}(\mathrm{T})$ & -39.041443 & -39.017528 & -0.651 \\
\hline & B3LYP & -39.153277 & -39.145220 & -0.219 \\
\hline & X3LYP & -39.130220 & -39.120080 & -0.276 \\
\hline & M06 & -39.116865 & -39.103650 & -0.360 \\
\hline & НCTH & -39.159379 & -39.149233 & -0.276 \\
\hline & TPSS & -39.166753 & -39.151923 & -0.404 \\
\hline & B97D3 & -39.126170 & -39.116682 & -0.258 \\
\hline & mPW2PLYP & -39.104973 & -39.088795 & -0.440 \\
\hline & B2PLYP & -39.104830 & -39.088783 & -0.437 \\
\hline \multirow[t]{13}{*}{ cc-pVTZ } & CASSCF & -38.970892 & -38.922769 & -1.310 \\
\hline & CASPT2 & -39.068241 & -39.061653 & -0.179 \\
\hline & MRPT2 & -39.080086 & -39.088020 & 0.216 \\
\hline & CCSD & -39.074460 & -39.071221 & -0.088 \\
\hline & $\operatorname{CCSD}(\mathrm{T})$ & -39.077853 & -39.077433 & -0.011 \\
\hline & B3LYP & -39.168706 & -39.177582 & 0.242 \\
\hline & X3LYP & -39.145670 & -39.152510 & 0.186 \\
\hline & M06 & -39.131244 & -39.134280 & 0.083 \\
\hline & $\mathrm{HCTH}$ & -39.172728 & -39.177577 & 0.132 \\
\hline & TPSS & -39.179626 & -39.180900 & 0.035 \\
\hline & B97D3 & -39.141400 & -39.147786 & 0.174 \\
\hline & mPW2PLYP & -39.125402 & -39.127586 & 0.059 \\
\hline & B2PLYP & -39.125854 & -39.128549 & 0.073 \\
\hline \multirow[t]{13}{*}{ aug-cc-pVDZ } & CASSCF & -38.961275 & -38.926716 & -0.940 \\
\hline & CASPT2 & -39.038795 & -39.048415 & 0.262 \\
\hline & MRPT2 & -39.047047 & -39.069572 & 0.613 \\
\hline & CCSD & -39.045787 & -39.059058 & 0.361 \\
\hline & $\operatorname{CCSD}(\mathrm{T})$ & -39.048037 & -39.064910 & 0.459 \\
\hline & B3LYP & -39.157485 & -39.185323 & 0.758 \\
\hline & X3LYP & -39.134520 & -39.160560 & 0.709 \\
\hline & M06 & -39.120375 & -39.140653 & 0.552 \\
\hline & HCTH & -39.164496 & -39.190814 & 0.717 \\
\hline & TPSS & -39.170160 & -39.188804 & 0.507 \\
\hline & B97D3 & -39.130612 & -39.156568 & 0.706 \\
\hline & mPW2PLYP & -39.109371 & -39.129833 & 0.557 \\
\hline & B2PLYP & -39.109269 & -39.130302 & 0.572 \\
\hline Exp. $^{79}$ & & & & 0.652 \\
\hline Noro et al. ${ }^{78}$ & & & & 0.60 \\
\hline Curtiss et al. ${ }^{65}$ & & & & 0.66 \\
\hline Gill et al. ${ }^{66}$ & & & & 0.72 \\
\hline Proft et $a l .^{74}$ & & & & 0.83 \\
\hline Davidson et al..$^{80}$ & & & & 0.63 \\
\hline
\end{tabular}

The complete active spaces for $\mathrm{CH}_{2}$ and $\mathrm{CH}_{2}^{-}$are $\mathrm{CAS}(6,6)$ and $\mathrm{CAS}(7,6)$, respectively. 
Table 7 Electron affinities for $\mathrm{NH}_{2}\left(X^{2} B_{1}\right)$ calculated with CASSCF, CASPT2, MRPT2, CCSD, CCSD(T), B3LYP, X3LYP, M06, HCTH, TPSS, B97D3, mPW2PLYP, and B2PLYP methods

\begin{tabular}{|c|c|c|c|c|}
\hline Basis set & Method & $E\left(\mathrm{NH}_{2}\right) /($ a.u. $)$ & $E\left(\mathrm{NH}_{2}^{-}\right) /($a.u. $)$ & $\mathrm{EA} / \mathrm{eV}$ \\
\hline \multirow[t]{13}{*}{ cc-pVDZ } & CASSCF* & -55.614243 & -55.529717 & -2.300 \\
\hline & CASPT2* & -55.720922 & -55.667410 & -1.456 \\
\hline & MRPT2* & -55.739575 & -55.698871 & -1.108 \\
\hline & CCSD & -55.730005 & -55.678952 & -1.389 \\
\hline & $\operatorname{CCSD}(\mathrm{T})$ & -55.732628 & -55.682705 & -1.358 \\
\hline & B3LYP & -55.877244 & -55.841049 & -0.985 \\
\hline & X3LYP & -55.850860 & -55.812470 & -1.045 \\
\hline & M06 & -55.836867 & -55.803183 & -0.917 \\
\hline & НCTH & -55.871626 & -55.840280 & -0.853 \\
\hline & TPSS & -55.884124 & -55.844064 & -1.090 \\
\hline & B97D3 & -55.842848 & -55.806508 & -0.989 \\
\hline & mPW2PLYP & -55.818825 & -55.776401 & -1.154 \\
\hline & B2PLYP & -55.818908 & -55.776758 & -1.147 \\
\hline \multirow[t]{13}{*}{ cc-pVTZ } & CASSCF* & -55.633622 & -55.571764 & -1.683 \\
\hline & CASPT2* & -55.780268 & -55.762187 & -0.492 \\
\hline & MRPT2* & -55.799332 & -55.798204 & -0.031 \\
\hline & CCSD & -55.787983 & -55.771587 & -0.446 \\
\hline & $\operatorname{CCSD}(\mathrm{T})$ & -55.793616 & -55.780313 & -0.362 \\
\hline & B3LYP & -55.903095 & -55.895482 & -0.207 \\
\hline & X3LYP & -55.876790 & -55.866940 & -0.268 \\
\hline & M06 & -55.858833 & -55.850469 & -0.228 \\
\hline & НСТН & -55.895171 & -55.889967 & -0.142 \\
\hline & TPSS & -55.907703 & -55.895617 & -0.329 \\
\hline & B97D3 & -55.867647 & -55.859035 & -0.234 \\
\hline & mPW2PLYP & -55.853260 & -55.841357 & -0.324 \\
\hline & B2PLYP & -55.854298 & -55.843271 & -0.300 \\
\hline \multirow[t]{13}{*}{ aug-cc-pVDZ } & CASSCF* & -55.629003 & -55.587679 & -1.125 \\
\hline & CASPT2* & -55.738090 & -55.753804 & 0.428 \\
\hline & MRPT2* & -55.749258 & -55.789388 & 1.092 \\
\hline & CCSD & -55.747825 & -55.763095 & 0.416 \\
\hline & $\operatorname{CCSD}(\mathrm{T})$ & -55.751737 & -55.771696 & 0.543 \\
\hline & B3LYP & -55.890973 & -55.918018 & 0.736 \\
\hline & X3LYP & -55.864780 & -55.889880 & 0.683 \\
\hline & M06 & -55.848869 & -55.872388 & 0.640 \\
\hline & НCTH & -55.885583 & -55.919565 & 0.925 \\
\hline & TPSS & -55.896401 & -55.918369 & 0.598 \\
\hline & B97D3 & -55.856069 & -55.884304 & 0.768 \\
\hline & mPW2PLYP & -55.833503 & -55.856586 & 0.628 \\
\hline & B2PLYP & -55.833719 & -55.858084 & 0.663 \\
\hline \multirow[t]{3}{*}{ aug-cc-pVDZ } & $\mathrm{CASSCF}^{* *}$ & -55.633544 & -55.607763 & -0.702 \\
\hline & CASPT2** & -55.738527 & -55.762315 & 0.647 \\
\hline & MRPT2** & -55.753396 & -55.781877 & 0.775 \\
\hline Exp. $^{81}$ & & & & 0.77 \\
\hline Curtiss et al. ${ }^{65}$ & & & & 0.77 \\
\hline Gill et al. ${ }^{66}$ & & & & 0.64 \\
\hline Yeager et al. ${ }^{67}$ & & & & 0.53 \\
\hline Ortiz $^{68}$ & & & & 0.68 \\
\hline Proft et al..$^{74}$ & & & & 0.79 \\
\hline Roos et al..$^{82}$ & & & & 0.73 \\
\hline
\end{tabular}

* The complete active spaces for $\mathrm{NH}_{2}$ and $\mathrm{NH}_{2}^{-}$are $\mathrm{CAS}(5,6)$ and $\mathrm{CAS}(6,6)$, respectively.

**The complete active spaces for $\mathrm{NH}_{2}$ and $\mathrm{NH}_{2}^{-}$are $\mathrm{CAS}(7,7)$ and $\mathrm{CAS}(8,7)$, respectively. 


\section{Conclusions}

The electron affinities of $\mathrm{F}, \mathrm{Cl}, \mathrm{OH}, \mathrm{SH}, \mathrm{CN}, \mathrm{CH}_{2}$, and $\mathrm{NH}_{2}$ calculated with CASSCF, CASPT2, MRPT2, CCSD, CCSD(T), B3LYP, X3LYP, M06, HCTH, TPSS, B97D3, mPW2PLYP, and B2PLYP are presented in this study at four levels of basis sets, cc-pVDZ, cc-pVTZ, aug-cc-pVDZ, and aug-cc-pVTZ. MRPT2 results are in very close agreement with the experimental results to within $0.1 \mathrm{eV}$. Its overall performance is the best among these methods. Density functional theories as a whole are reliable approaches at the aug-cc-pVDZ level though the performance of each individual functional is dependent on the system studied. The performance of CASSCF is inferior to all other methods tested in this study. The wrong sign of the electron affinities of $\mathrm{CH}_{2}$ and $\mathrm{NH}_{2}$ calculated with CASSCF even at aug-cc-pVDZ level indicates that CASSCF wavefunction may be not a reliable choice at least for the systems studied here.

It is shown in this work that the diffuse functions play an important role in achieving an accurate result. On the other hand, it is also seen from the results of $\mathrm{OH}$ and $\mathrm{NH}_{2}$ that a relatively large size of the complete active space has a significant effect on the accuracy of the results of MRPT2 since it will introduce higher level of excitation configurations into the zeroth order wavefunction as well as the perturbation wavefunction.

\section{References}

(1) Chen, F. W. Computaional Method in Quantum Chemistry; Science Press: Beijing, 2008; pp 70-72. [陈飞武. 量子化学中的 计算方法. 北京: 科学出版社, 2008: 70-72.]

(2) Feng, X. J.; Li, Q. S. Acta Phys. -Chim. Sin. 2004, 20, 1172. [封学军, 李前树. 物理化学学报, 2004, 20, 1172.] doi: 10.3866/PKU.WHXB20040923

(3) Huang, J. G.; Shi, T. Q.; Luo, Q. Y. Acta Chim. Sin. 2004, 62, 236. [黄俭根, 施踏青, 罗秋艳. 化学学报, 2004, 62, 236.]

(4) Li, H. X.; Tang, H. A.; Yang, S.; Xiao, T. Acta Phys. -Chim. Sin. 2007, 23, 1781. [李会学, 唐惠安, 杨 声, 萧泰. 物理化学学 报, 2007, 23, 1781.] doi: 10.3866/PKU.WHXB20071124

(5) Ding, X. L.; Wu, J. M.; Xu, X. Chem. J. Chin. Univ. 2008, 29, 396. [丁秀丽, 吴剑鸣, 徐 昕. 高等学校化学学报, 2008, 29, 396.]

(6) Peach, M. J. G.; Proft, F. D.; Tozer, D. J. J. Phys. Chem. Lett. 2010, 1, 2826. doi: 10.1021/jz101052q

(7) Li, W. W.; Hou, R. B.; Sun, Y. L. Acta Phys. -Chim. Sin. 2010, 26, 2772. [李伟伟, 侯若冰, 孙彦丽. 物理化学学报, 2010, 26, 2772.] doi: 10.3866/PKU.WHXB20101004

(8) Borgoo, A.; Tozer, D. J. J. Phys. Chem. A 2012, 116, 5497. doi: 10.1021/jp302801q

(9) Wei, M. J.; Jia, D. Q.; Chen, F. W. Acta Phys. -Chim. Sin. 2013, 29, 1441. [韦美菊, 贾德强, 陈飞武. 物理化学学报, 2013, 29, 1441.] doi: 10.3866/PKU.WHXB201304221

(10) Fu, R.; Lu, T.; Chen, F. W. Acta Phys. -Chim. Sin. 2014, 30, 628. [付 蓉, 卢 天, 陈飞武. 物理化学学报, 2014, 30, 628.] doi:
10.3866/PKU.WHXB201401211

(11) Cave, R. J.; Davidson, E. R. J. Chem. Phys. 1988, 88, 5770. doi: $10.1063 / 1.454535$

(12) Andersson, K.; Malmqvist, P. A.; Roos, B. O. J. Chem. Phys. 1992, 96, 1218. doi: 10.1063/1.462209

(13) Hirao, K. Chem. Phys. Lett. 1992, 190, 374. doi: 10.1016/00092614(92)85354-D

(14) Hirao, K. Chem. Phys. Lett. 1992, 196, 397. doi: 10.1016/00092614(92)85710-R

(15) Kozlowski, P. W.; Davidson, E. R. J. Chem. Phys. 1994, 100, 3672. doi: 10.1063/1.466355

(16) Kozlowski, P. W.; Davidson, E. R. Chem. Phys. Lett. 1994, 226, 440. doi: 10.1016/0009-2614(94)00763-2

(17) Hoffmann, M. R. J. Phys. Chem. 1996, 100, 6125. doi: 10.1021/jp952753r

(18) Mahapatra, U. S.; Datta, B.; Mukherjee, D. J. Phys. Chem . A 1999, 103, 1822. doi: 10.1021/jp9832995

(19) Khait, Y. G.; Song, J.; Hoffmann, M. R. J. Chem. Phys. 2002, 117, 4133. doi: 10.1063/1.1497642

(20) Wang, Y. B.; Gang, Z. T.; Su, K. H.; Wen, Z. Y. Scientia Sinica Chimica 2000, 30, 543. [王育涁, 甘正汀, 苏克和, 文振翼. 中国 科学: 化学, 2000, 30, 543.]

(21) Angeli, C.; Cimiraglia, R.; Evangelisti, S.; Leininger, T.; Malrieu, J. P. J. Chem. Phys. 2001, 114, 10252. doi: 10.1063/1.1361246

(22) Angeli, C.; Bories, B.; Cavallini, A.; Cimiraglia, R. J. Chem. Phys. 2006, 124, 054108. doi: 10.1063/1.2148946

(23) Chen, F.; Davidson, E. R.; Iwata, S. Int. J. Quantum Chem. 2002, 86, 256. doi: 10.1002/qua.1105

(24) Rolik, Z.; Szabados, Á.; Surján, P. R. J. Chem. Phys. 2003, 119, 1922. doi: 10.1063/1.1584424

(25) Szabados, A.; Rolik, Z.; Tóth, G.; Surján, P. R. J. Chem. Phys. 2005, 122, 114104. doi: 10.1063/1.1862235

(26) Chen, F. Sci. China-Chem. 2007, 50, 483. doi: 10.1007/s11426007-0074-0

(27) Chen, F. W. Acta Phys. -Chim. Sin. 2007, 23, 1360. [陈飞武. 物 理化学学报, 2007, 23, 1360.] doi: 10.1016/S18721508(07)60072-2

(28) Fink, R. F. Chem. Phys. 2009, 356, 39. doi: 10.1016/j.chemphys. 2008.10.004

(29) Chen, Z.; Song, J.; Shaik, S.; Hiberty, P. C.; Wu, W. J. Phys. Chem. A 2009, 113, 11560.

(30) Chen, F. J. Chem. Theory Comput. 2009, 5, 931. doi: $10.1021 / \mathrm{ct} 800546 \mathrm{~g}$

(31) Chen, F.; Wei, M.; Liu, W. Sci. China-Chem. 2011, 54, 446. doi: 10.1007/s11426-010-4199-1

(32) Kobayashi, M.; Szabados, Á.; Nakai, H.; Surján, P. R. J. Chem. Theory Comput. 2010, 6, 2024. doi: 10.1021/ct1001939

(33) Mao, S.; Cheng, L.; Liu, W.; Mukherjee, D. J. Chem. Phys. 2012, 136, 024105. doi: $10.1063 / 1.3672083$

(34) Mao, S.; Cheng, L.; Liu, W.; Mukherjee, D. J. Chem. Phys. 2012, 136, 024106. doi: 10.1063/1.3672085

(35) Chen, Z.; Hoffmann, M. R. J. Chem. Phys. 2012, 137, 014108. 
doi: $10.1063 / 1.4731634$

(36) Lei, Y.; Wang, Y.; Han, H.; Song, Q.; Suo, B.; Wen, Z. J. Chem. Phys. 2012, 137, 144102. doi: 10.1063/1.4757264

(37) Xu, E.; Li, S. J. Chem. Phys. 2013, 139, 174111. doi: $10.1063 / 1.4828739$

(38) Chen, F.; Fan, Z. J. Comput. Chem. 2014, 135, 121.

(39) Liu, W.; Hoffmann, M. R. Theor. Chem. Acc. 2014, 133, 1481. doi: 10.1007/s00214-014-1481-x

(40) Chen, Z.; Chen, X.; Ying, F.; Gu, J.; Zhang, H.; Wu, W. J. Chem. Phys. 2014, 141, 134118. doi: 10.1063/1.4896534

(41) Roos, B.; Taylor, P.; Siebahn, P. Chem. Phys. 1980, 48, 157. doi: 10.1016/0301-0104(80)80045-0

(42) Cizek, J. Adv. Chem. Phys. 1969, 14, 35.

(43) Purvis, G. D.; Bartlett, R. J. J. Chem. Phys. 1982, 76, 1910. doi: $10.1063 / 1.443164$

(44) Scuseria, G. E.; Janssen, C. L.; Schaefer, H. F., III. J. Chem. Phys. 1988, 89, 7382. doi: 10.1063/1.455269

(45) Scuseria, G. E.; Schaefer, H. F., III. J. Chem. Phys. 1989, 90, 3700. doi: 10.1063/1.455827

(46) Pople, J. A.; Head-Gordon, M.; Raghavachari, K. J. Chem. Phys. 1987, 87, 5968. doi: 10.1063/1.453520

(47) Becke, A. D. Phys. Rev. A 1988, 38, 3098.

(48) Beck, A. D. J. Chem. Phys. 1993, 98, 5648.

(49) Lee, C.; Yang, W.; Parr, R. G. Phys. Rev. B 1988, 37, 785.

(50) Xu, X.; Goddard, W. A., III. Proc. Natl. Acad. Sci. U. S. A. 2004, 101, 2673. doi: 10.1073/pnas.0308730100

(51) Zhao, Y.; Truhlar, D. G. Theor. Chem. Acc. 2008, 120, 215.

(52) Hamprecht, F. A.; Cohen, A. J.; Tozer, D. J.; Handy, N. C. J. Chem. Phys. 1998, 109, 6264. doi: 10.1063/1.477267

(53) Tao, J.; Perdew, J.; Staroverov, V.; Scuseria, G. Phys. Rev. Lett. 2003, 91, 146401. doi: 10.1103/PhysRevLett.91.146401

(54) Grimme, S.; Ehrlich, S.; Goerigk, L. J. Comp. Chem. 2006, 27, 1787. doi: $10.1002 /$ jcc. 20495

(55) Grimme, S. J. Chem. Phys. 2006, 124, 034108. doi: $10.1063 / 1.2148954$

(56) Schwabe, T.; Grimme, S. Phys. Chem. Chem. Phys. 2006, 8 , 4398. doi: 10.1039/b608478h

(57) Dunning, T. H. J. Chem. Phys. 1989, 90, 1007. doi: $10.1063 / 1.456153$

(58) Woon, D. E.; Dunning, T. H. J. Chem. Phys. 1993, 98, 1358. doi: $10.1063 / 1.464303$

(59) Schmidt, M. W.; Baldridge, K. K.; Boatz, J. A.; Elbert, S. T.; Gordon, M. S.; Jensen, J. H.; Koseki, S.; Natsunaga, N.; Nguyen, K. A.; Su, S. J.; Windus, T. L.; Dupuis, M.; Montgomery, J. A. J. Comput. Chem. 1993, 14, 1347.

(60) Frisch, M. J.; Trucks, G. W.; Schlegel, H. B.; et al. Gaussian 09W, Revision D.01; Gaussian Inc.: Pittsburgh, PA, 2009.

(61) Werner, H. J.; Knowles, P. J.; Lindh, R.; MAnby, F. R.; Schütz,
M. et al. Molpro, 2009.1, a Package of ab initio Programs; See http://www.molpro.net.

(62) Adamowicz, L.; Bartlett, R. J. Chem. Phys. 1986, 84, 6837. doi: $10.1063 / 1.450688$

(63) Pople, J. A.; Head-Gordon, M.; Fox, D. J.; Raghavachari, K.; Curtiss, L. A. J. Chem. Phys. 1989, 90, 5622. doi: $10.1063 / 1.456415$

(64) Blondel, C.; Cacciani, P.; Delsart, C.; Trainham, R. Phys. Rev. A 1989, 40, 3698. doi: 10.1103/PhysRevA.40.3698

(65) Curtiss, L. A.; Raghavachari, K.; Trucks, G. W.; Trucks, G. W.; Pople, J. A. J. Chem. Phys. 1991, 94, 7221. doi: 10.1063/ 1.460205

(66) Gill, P. M. W.; Johnson, B. G.; Pople, J. A.; Frisch, M. J. Chem. Phys. Lett. 1992, 197, 499. doi: 10.1016/0009-2614(92)85807-M

(67) Yeager, D. L.; Nichols, J. A.; Golab, J. T. J. Chem. Phys. 1992, 97, 8441. doi: 10.1063/1.463414

(68) Ortiz, J. V. Chem. Phys. Lett. 1998, 296, 494. doi: 10.1016/S0009-2614(98)01067-7

(69) Jana, D.; Datta, D.; Mukherjee, D. Chem. Phys. 2006, 329, 290. doi: 10.1016/j.chemphys.2006.08.025

(70) Yoshida, T.; Mizushima, Y.; Iguchi, K. J. Chem. Phys. 1988, 89, 5815. doi: 10.1063/1.455557

(71) Hotop, H.; Lineberger, W. C. J. Phys. Chem. Ref. Data 1975, 4, 539. doi: 10.1063/1.555524

(72) Huber, K. P.; Herzberg, G. Molecular Spectra and Molecular Structure IV: Constants of Diatomic Molecules; Van Nostrand Reinhold: New York, 1979.

(73) Schulz, P. A.; Mead, R. D.; Jones, P. L.; Linebergert W. C. J. Chem. Phys. 1982, 77, 1153. doi: 10.1063/1.443980

(74) Proft, F. D.; Geerlings, P. J. Chem. Phys. 1997, 106, 3270. doi: 10.1063/1.473796

(75) Frenking, G.; Koch, W. J. Chem. Phys. 1986, 84, 3224. doi: 10.1063/1.450832

(76) Steiner, B. J. Chem. Phys. 1968, 49, 5097. doi: 10.1063/1.1670004

(77) Berkowitz, J.; Chupka W. A.; Walter, T. A. J. Chem. Phys. 1969, 50, 1497. doi: 10.1063/1.1671233

(78) Noro, T.; Yoshimine, M. J. Chem. Phys. 1989, 91, 3012. doi: 10.1063/1.456922

(79) Leopold, D. G.; Murray, K. K.; Stevens-Miller, A. E.; Lineberge, W. C. J. Chem. Phys. 1985, 83, 4849. doi: 10.1063/1.449746

(80) Feller, D.; McMurchie, L. E.; Borden, W. T.; Davidson, E. R. J. Chem. Phys. 1982, 77, 6134. doi: 10.1063/1.443858

(81) Wickham-Jones, C. T.; Ervin, K. M.; Ellison, G. B.; Lineberge, W. C. J. Chem. Phys. 1989, 91, 2762. doi: 10.1063/1.456994

(82) Merchan, M.; Roos, B. O. Chem. Phys. Lett. 1991, 184, 346. doi: 10.1016/0009-2614(91)85135-J 